and intensive treatment. If the condition is diagnosed early and treated appropriately the prognosis is much better than that in patients with cardiogenic shock caused predominantly by left ventricular dysfunction. ${ }^{28} 29$

Clinical Research Fellow in Cardiology,

J L CAPLIN

Cardiac Unit,

Massachusetts General Hospital,

Boston,

MA 02114, United States

1 Wilson BC, Cohn JN. Right ventricular infarction: clinical and pathophysiologic considerations. Ann Intern Med 1988;33:295-310.

2 Ratliff NB, Hackel DB. Combined right and left ventricular infarction: pathogenesis and clinicopathologic correlations. Am f Cardiol 1980;45:217-21.

3 Shah PK, Maddahi J, Berman DS, Pichler M, Swan HJC. Scintigraphically detected predominant right ventricular dysfunction in acute myocardial infarction: clinical and hemodynamic right ventricular dysfunction in acute myocardial infarction: clinical and hemodyna

4 Dell'Italia LJ, Starling MR, O'Rourke RA. Physical examination for exclusion of hemodynamically important right ventricular infarction. Ann Intern Med 1983;99:608-11.

5 Andersen HR, Neilson D, Falk E. Right ventricular infarction: diagnostic value of ST elevation in lead III exceeding that of lead II during inferior/posterior infarction and comparison of right chest leads V3R to V7R. Am Heart f 1989;117:82-6.

6 Lopez-Sendon J, Coma-Canella I, Alcasena S, Seoane J, Gamello C. Electrocardiographic findings in acute right ventricular infarction: sensitivity and specificity of electrocardiographic alterations in right precordial leads V4R, V3R, V1, V2 and V3. $\mathcal{~ A m ~ C o l l ~ C a r d i o l ~ 1 9 8 5 ; 6 : 1 2 7 3 - 9 . ~}$

7 Cohn JN, Guiha NH, Broder MI, Lima CJ. Right ventricular infarction. Clinical and hemodynamic features. Am f Cardiol 1974;33:209-14.

8 Lopez-Sendon J, Coma-Canella I, Gammallo C. Sensitivity and specificity of hemodynamic criteria in the diagnosis of acute right ventricular infarction. Circulation 1981;64:515-26.

9 Caplin JL, Dymond DS, Flatman WD, Spurrell RAJ. Global and regional right ventricular function after acute myocardial infarction: dependence upon the site of left ventricular infarction. Br Heart $f$ 1987;58:101-9.

10 Rigo P, Murray M, Taylor DR, et al. Right ventricular dysfunction detected by gated scintiphotography in patients with acute inferior myocardial infarction. Circulation 1975;52: 268-74.

11 Wackers FJT, Lie KS, Sokele EB, Res J, van der Schoot JB, Durrer D. Prevalence of right ventricular involvement in inferior wall infarction assessed with myocardial imaging with thallium 201 and technetium 99m pyrophosphate. Am $\mathcal{J}$ Cardiol 1978;42:358-62.
12 Bellamy GR, Rasmussen HH, Nasser FN, Wiseman JC, Cooper RA. Value of two-dimensional echocardiography, electrocardiography and clinical signs in detecting right ventricular infarction. Am Heart I 1986;112:304-9.

13 Clark G, Strauss HD, Roberts R. Dobutamine vs furusemide in the treatment of cardiac failure due to right ventricular infarction. Chest 1980;77:220-3.

$14 \mathrm{Jaffe} \mathrm{JH}$, Martin WR. Narcotic analgesics and antagonists. In: Goodman LS, Gilman A, eds. Goodman and Gilman's, the pharmacological basis of therapeutics. 5th ed. New York: MacMillan Goodman and Gilman's,

15 Goldstein JA, Vlahakes GJ, Verrier ED, et al. Volume loading improves low cardiac output in experimental right ventricular infarction. $f$ Am Coll Cardiol 1983;2:270-8.

16 Lorell B, Palacios I, Daggett WM, Jacobs ML, Fowler BN, Newell JB. Right ventricula distention and left ventricular compliance. Am $\mathcal{F}$ Physiol 1981;240:H87-98.

17 Elzinga G, van Grondell R, Westerhof N, van den Bos GC. Ventricular interference. Am $\mathcal{F}$ Physiol 1974;226:941-7.

18 Dell'Italla LJ, Starling MR, Blumhardt R, Lasher JC, O'Rourke RA. Comparative effects of volume loading, dobutamine and nitroprusside on patients with predominant right ventricular infarction. Circulation 1985;72:1327-35.

19 Gillespie TA, Ambos HD, Sobel BE, Roberts R. Effects of dobutamine in patients with acute myocardial infarction. Am $\mathcal{J}$ Cardiol 1977;39:588-94.

20 Goldstein JA, Vlahakes GJ, Verrier ED, et al. The role of right ventricular systolic dysfunction and elevated intrapericardial pressure in the genesis of low cardiac output in experimental right elevated intrapericardial pressure in the genesis of
ventricular infarction. Circulation 1982;65:513-22.

21 Yin FPC, Guzman PA, Brin KP, et al. Effect of nitroprusside on hydraulic vascular loads on the right and left ventricle of patients with heart failure. Circulation 1983;66:1330-9.

22 Love JC, Hafferjee CI, Gore JM, Alpert JS. Reversibility of hypotension and shock by atrial or atrioventricular sequential pacing in patients with right ventricular infarction. Am Heart $f$ 1984;108:5-13.

23 Shires DB. Rupture of the right ventricle. fAMA 1968;203:888-90.

24 Higgin SG. Rupture of interventricular septum and right ventricle after acute myocardia infarction. Aust NZ F Med 1981;11:46-7.

25 Reitveld AP, Merrman L, Essed CE, Trimbos JBMJ, Hegemeijer F. Right to left shunt, with severe hypoxemia, at the atrial level in a patient with hemodynamically important righ ventricular infarction. $\mathcal{f} \mathrm{Am}$ Coll Cardiol 1983;2:776-9.

26 Lader E, Colvin S, Tunick P. Myocardial infarction complicated by rupture of both ventricular septum and right ventricular papillary muscle. Am $\mathcal{C}$ Cardiol 1983;52:423-4.

27 Stowers SA, Leiboff RH, Wasserman AG, Katz RJ, Bren GB, Hsu I. Right ventricular thrombus formation associated with acute myocardial infarction: diagnosis by 2 dimensional echocardiography. Am J Cardiol 1983;52:912-3.

28 Brown KA, DeSanctis RW, DiCola V, Boucher CA, Pohost GM, Okada RD. Long term exercise and hemodynamic follow-up in patients with previous right ventricular myocardial infarction. Am Heart $\mathcal{O}$ 1986;112:1321-2.

29 Leinbach RC, DeSanctis RW, Goldman R. Shock, cardiac arrest and orthostatic hypotension. In Eagle KA, Haber E, DeSanctis RW, Austen WG, eds. The practice of cardiology. 2nd ed. Boston, Toronto: Little, Brown, 1989:34.

\title{
Non-migrainous headaches
}

\section{Classification and management}

Headaches are common and are of many different types, most of them benign. Not surprisingly, different names and systems of classification abound. In an attempt to sort out the confusion the International Headache Society has produced a new set of guidelines, classifying headaches into 13 different groups (box).' (For details of migraine see next week's issue.)

Tension type headaches, which may be either episodic or chronic, are the commonest headaches and include muscle contraction headache, stress headache, essential headache, and psychogenic headache.' These types of headache typically press "like a tight hat"; the pain is mild to moderate, bilateral, and does not worsen with normal physical activity. Vomiting is unusual, but photophobia and phonophobia may occur. Headaches in this group are further subdivided into those with abnormalities of the pericranial muscles diagnosed either by palpation or by electromyographic evidence of increased muscle activity at rest and those without such abnormalities.

Treatment of tension type headaches is unsatisfactory. A detailed history with attention to symptoms of anxiety and depression should be taken and a careful examination, including palpation of the head, performed. Patients should be given an explanation of the possible mechanism of the headaches. They will commonly have received an unsympathetic hearing from their doctor; general practitioners are well placed to recognise the social and family stresses their patients may be suffering, and their support is important for the successful management of this condition. Psychotherapy, counselling, and emotional support may be of value. Psychiatric referral is likely to be rejected by many patients until other therapeutic measures have been tried. Muscle contraction headaches may also be the response to localised disease of the head, temporomandibular joint dysfunction, cervical spondylosis, eye muscle disorders, and sinus diseases, ${ }^{2}$ which should of course be treated if found.

Episodic tension headaches with a prominent muscle component may be helped by simple massage. Analgesics do not usually help, though non-steroidal anti-inflammatory drugs may be useful. ${ }^{3}$ Amitriptyline and other tricyclic drugs may non-specifically raise the pain threshold, and full doses should be given for several months in resistant cases. Adding propranolol may provide an extra therapeutic benefit. ${ }^{2}$

Treating chronic tension type headache is even more difficult. Sedative drugs such as benzodiazepines have commonly been prescribed, but these should be avoided as tolerance usually results and the problems of chronic sedative usage may emerge. Episodic use of these drugs may sometimes be helpful for severe bouts of pain. Their dose should be rapidly tailed off once the pain has been controlled. Other non-pharmacological measures should be considered. Experience in America of biofeedback techniques, behavioural programmes, and relaxation suggest that these may be helpful. ${ }^{+}$Few controlled trials have, however, been done to support these claims, and these treatments are not easily obtained in Britain.

Tension headache and migraine commonly coexist, and coding them separately in order of importance is preferable to using the term "combination headaches." Treatment is directed towards the more important of the two, though prophylaxis against migraine is easier to prescribe. 


\section{Classification of headache ${ }^{\star}$}

\section{Migraine}

Tension type headache

Cluster headache and chronic paroxysmal hemicrania

Miscellaneous headaches not associated with structural lesion

Headache associated with:

Head trauma

Vascular disorders

Non-vascular intracranial disorder

Substances or their withdrawal

Non-cephalic infection

Metabolic disorder

Headache or facial pain associated with disorders of cranium, neck, eyes, ears, nose, sinuses, teeth, mouth, or other facial or cranial structures

Cranial neuralgias, nerve trunk pain, and deafferentiation pain

Headaches not classifiable

^According to the International Headache Society.'

Cluster headaches are very severe unilateral head pains which occur in bouts (hence cluster) of several weeks separated by remission lasting from months to years. Attacks last from 15 minutes to three hours, occurring on alternate days up to eight times a day for as long as the cluster lasts. Pains may be felt around the orbit, forehead, or temporal regions and may be accompanied by conjunctival injection, miosis and ptosis (Horner's syndrome), or oedema of the eyelid. One in 10 patients presents with chronic symptoms or develops them from the intermittent variety. Patients are usually young men; fewer than one third are women, who usually present later. The severity of the pain fully justifies its description as the "suicide headache"-patients may be driven to hit their head against a wall. The intensity of the pain and the side affected may vary from attack to attack. If Horner's syndrome occurs it is commonly permanent. Alcohol may provoke attacks, but few other provocative agents have been identified. Between bouts provocation by alcohol resolves. The diagnosis is usually apparent from the history, but further investigation with computed tomography is indicated if atypical features or neurological signs other than Horner's syndrome are present.

Treatment of cluster headaches is unsatisfactory. Lithium carbonate is now probably the best treatment for both acute and chronic forms, although renal, thyroid, or cardiovascular disorders are contraindications to its use. Serum concentrations of the drug should be monitored to prevent toxicity. Treatment with steroids (prednisolone $40 \mathrm{mg}$ a day tailing off over four weeks) may cut short a bout and be used on its own for the first bout or with lithium carbonate for recurrent attacks. Ergotamine may be used to prevent attacks within a bout if their pattern is known ("alarm clock headaches"). Side effects are common with ergotamine because regular dosing may be necessary. No more than $6 \mathrm{mg}$ a day should be taken with one day off each week to check if the bout has finished. Methysergide is a useful second line drug with daily doses of up to $6 \mathrm{mg}$, though courses should be interrupted every four months (as for migraine). Pizotifen is probably less effective than methysergide. Oxygen treatment may provide relief during the attack and should work within 10 minutes after it has been started. For patients with refractory attacks combinations of the above may be used carefully. Nonsteroidal anti-inflammatory drugs may be tried. For patients with continuing severe pain neurosurgery has been suggested, although its efficacy has not been established.

Chronic paroxysmal hemicrania differs from cluster headaches in the brevity of the attack, which may last only minutes (range three to 45 minutes) and may occur up to 40 times a day. Once established, it pursues a chronic, unremitting course unless modified with drugs. ${ }^{5}$ Almost invariably a unilateral pain, it otherwise resembles cluster headaches with autonomic disturbance, facial sweating, Horner's syndrome, and so on. Its main feature is its invariable and absolute response to small doses of indomethacin (up to $150 \mathrm{mg}$ a day). Doses from 25 to $100 \mathrm{mg}$ a day protect against relapse.

The group designated miscellaneous headaches comprises disorders not associated with structural lesions. Such headaches are recognised by their typical symptoms, and further investigation is usually unnecessary. Idiopathic stabbing headache, previously known as "ice pick" pains or cephalalgia fugax, is extremely common, especially in subjects with migraine. The pains are intense and stabbing, lasting for a fraction of a second, commonly coming in bouts, and are usually localised to the distribution of the first division of the trigeminal nerve. Reassurance is all that is usually required. If not, indomethacin $25 \mathrm{mg}$ thrice daily may be prescribed.'

External compression headache refers to neuralgic pains that follow compression of a cutaneous cephalic nerve-for example, by swimming goggles. ${ }^{6}$ Cold stimulus headaches follow either external application of cold or cold food or drink - for example, ice creams. For both these headaches the remedy is straightforward.

Benign cough headache ${ }^{7}$ should be diagnosed only after structural lesions have been excluded by computed tomography; sometimes myelography or magnetic resonance imaging is required to rule out hernia of the hind brain. ${ }^{8}$ Benign exertional headaches are brought on by exercise and may take the form of migraine. When these are troublesome one of several drugs taken before exercise-such as propranolol and indomethacin - may be helpful. In more severe cases ergotamine or methysergide may be useful.

Headache associated with sexual activity may cause great anxiety, and even if patients are sufficiently reassured of its usually benign nature their sex lives may suffer and they may become depressed. A variant of exertional headache, this type of headache may be helped by similar therapeutic manoeuvres. Patients with the explosive type of "coital cephalalgia" occurring for the first time should be admitted to hospital to exclude subarachnoid haemorrhage. This also applies to patients with their first "thunderclap" headache, ${ }^{9}$ which may be unrelated to sexual activity.

Other headaches are recognised by their association with provocative agents - or with clinical signs (see box). Papilloedema is present in benign intracranial hypertension, and focal neurological signs are present in stroke. Headache, however, may be the presenting symptom of a serious disorder without any signs, although brain tumours usually present with symptoms and signs of raised intracranial pressure-for example, morning headache, effortless vomiting, provocation by coughing and straining, and papilloedema. These features or progressive focal signs should always lead to computed tomography to rule out intracranial neoplasms. Tumours may occasionally mimic other headache symptoms, and the character of the symptom (say, whether throbbing or pressing) may be unhelpful. A short history of headache (less than four months) especially if localised or occurring for the first time in older patients should be investigated.

Temporal arteritis should be considered in patients aged over 50 with headaches. ${ }^{10}$ Other suggestive symptoms are 
tenderness of the scalp (for example, when brushing hair), general malaise, and exquisite pain on palpation over the temporal artery. If temporal arteritis is suspected and especially if the erythrocyte sedimentation rate is increased prednisolone $60 \mathrm{mg}$ or intravenous steroids, or both, should be given immediately as delay may result in blindness.

Metabolic causes of headache are rare, but the morning headache of sleep apnoea is becoming increasingly recognised. Daytime sleeping and disturbed sleep with snoring in the presence of obesity and respiratory disease suggest sleep apnoea. The diagnosis requires nocturnal monitoring of the blood gas tensions, and treatment is directed at the underlying cause.

Cranial neuralgias, nerve trunk pain, and the pain of deafferentiation may be distinguished from other headaches by the distribution of pain along specific cranial nerves. Other signs of cranial nerve disease - for example, optic neuritis and the Tolosa-Hunt syndrome (granulomatous angiitis causing painful ophthalmoplegia) - may be found. Neuralgias need not be accompanied by signs - for example, trigeminal and glossopharyngeal neuralgia. Abnormal signs should always be investigated. Trigeminal neuralgia, a relapsing and remitting disorder, is best treated for as long as possible with drugs, carbamazepine being the best. ${ }^{11}$ Its dose may be increased to the maximum tolerated and in resistant cases phenytoin added. Surgery may be needed, and in this case radio frequency rhizotomy is probably the best treatment.

Consultant Neurologist,

CHRIS CLOUGH

Brook General Hospital,

London SE18 4LW

1 Headache Classification Committee of the International Headache Society. Classification and diagnostic criteria for headache disorders, cranial neuralgia and facial pain. Cephalalgia 1988;8(suppl 7):9-96.

2 Elkind AH. Muscle contraction headache. Postgrad Med 1987;8:203-18.

3 Miller DS, Talbot CA, Simpson W, Korey A. A comparison of naproxen sodium, acetaminophen and placebo in the treatment of muscle contraction headache. Headache 1987;27:392-6.

4 Diamond S. Treatment of chronic headache, a non-pharmacological approach. Postgrad Med 1987;81:91-6.

5 Sjaastad O. Chronic paroxysmal hemicrania (CPH). In: Clifford Rose F, ed. Handbook of clinical neurology. Vol 4(48). Headache. New York: Elsevier Science Publishers, 1986:257-66.

6 Pestronk A, Pestronk S. Goggle migraine. N Engl F Med 1983;308:226.

Symonds CP. Cough headache. Brain 1956;79:557-68.

8 Nightingale S, Williams B. Hind-brain hernia headache. Lancet 1987;i:731-4

Day JW, Raskin NH. Thunderclap headache: symptom of unruptured cerebral aneurysm. Lancet 1986;ii:1247-8.

10 Wijdicks EFM, Kerkhoff H, Van Gijn J. Long-term follow up of 71 patients wich thunderclap headache. Lancet 1968;ii:68-70.

11 Dalessio DJ. Trigeminal neuralgia. A practical approach to treatment. Drugs 1982;24:248-55.

\section{HIV and decontamination procedures}

\section{Heat is best}

The need to treat a novel, transmissible, and fatal disease has forced reconsideration of many established practices including the methods used to decontaminate instruments and equipment. Disinfectants have been over used, and the efficacy of some common disinfectants have not been fully assessed.

Instruments that enter areas of the body that are normally sterile must themselves be sterile; sterilisation may be achieved by autoclaving or using hot air ovens, alternatively presterilised equipment that is used only once may be used. Disinfectants are of little or no use for achieving complete sterility. Instruments that come into contact with intact mucous membranes must either be sterile or have undergone high level disinfection - that is, disinfection in which all microbes except bacterial spores are killed. Again this is best achieved by heat. Low risk instruments that come into contact only with intact skin may be treated with disinfectants or cleaned by washing. ${ }^{1}$ Using liquid disinfectants to sterilise instruments is best avoided - as has been known and accepted for years. The practical difficulties of ensuring the correct concentration of disinfectant, the correct acidity or alkalinity, the absence of protein, and accessibility to the microorganisms are well understood ${ }^{2}-$ even though the principles have not always been widely enough appreciated. The continued occurrence of outbreaks of infection associated with disinfectants indicates the widespread lack of understanding of the way they should be used. ${ }^{3-5}$ When they should be used is also a problem, and a recent survey in general practice showed that almost half of instruments that should have been sterile were being wrongly processed-often by chemical disinfection. ${ }^{6}$ Attitudes to decontamination also vary widely. For example, some practitioners feel that all vaginal speculums should be sterile whereas others consider that anything more than a soaking in disinfectant is impracticable and unrealistic. $^{\text {? }}$

Now Hanson and others have thrown doubt on the efficacy of alcohol in killing HIV in $10 \%$ serum dried on to surfaces. ${ }^{8}$ In contrast, other studies using different experimental conditions have shown that alcohol is effective against HIV. The findings of Hanson and others need validation, but it is important to put them into perspective. Using disinfectants to sterilise instruments is always unsatisfactory, and the demonstration that HIV may survive in these particular circumstances confirms that the methods currently in use are sometimes less than ideal.

The risks of transmitting pathogens in endoscopy units have long been known, ${ }^{9}$ and even though Hanson and others have shown that glutaraldehyde was effective when alcohol was not, this should not permit complacency. Our aim must be to stop using chemical disinfectants to sterilise instruments as soon as this is feasible.

Disinfectants are used in hospitals for their action against HIV with heat labile equipment and for spills of blood and other body fluids. Instruments other than fibreoptic endoscopes that are most commonly decontaminated by disinfectants are glass clinical thermometers, for which alcohol may be used. If this practice is to continue the cleanliness of thermometers before they are soaked in alcohol becomes of great importance; otherwise their modification or replacement should now be considered. When mopping up spills the main method of protection is to place a barriersuch as gloves and other protective clothing-between the person removing the spill and the infectious agents contained within it. Disinfectants may be valuable in inactivating agents in blood, but they should be regarded as a second line of defence.

There is a growing awareness of the need to improve decontamination methods, and guidelines recently produced by the British Medical Association will be valuable. ${ }^{10}$ Special problems occur, however: decontamination of some very fine surgical instruments, for example, may be extremely difficult and warrants further study. The activity of disinfectants 